\title{
Escherichia coli LT enterotoxin subunit A demonstrates partial toxicity independent of the nicking around Arg192
}

\author{
Takao Tsuji, ${ }^{1}$ Michio Kato, ${ }^{1}$ Hidetsugu Kawase, ${ }^{1}$ Seiji Imamura, ${ }^{1}$ \\ Hirofumi Kamiya, ${ }^{1}$ Yoshio Ichinose ${ }^{2}$ and Akio Miyama ${ }^{1}$
}

\author{
Author for correspondence: Takao Tsuji. Tel: +8156293 2433. Fax: + 81562932649. \\ e-mail: ttsuji@fujita-hu.ac.jp
}

1 Department of Microbiology, Fujita

Health University, School of Medicine, Toyoake,

Aichi, 470-11, Japan

2 Department of Bacteriology, Institute of Tropical Medicine, Nagasaki University, 1-12-4, Sakamoto, Nagasaki 852 , Japan

\begin{abstract}
A study was conducted into whether or not nicking of the A subunit of Escherichia coli LT enterotoxin at position Arg192 or its neighbouring amino acids Arg192 to The 195 is required for its toxicity. The toxic activity of mutants created by substitution or deletion at this position, which lacked ADP. ribosyltransferase activity in vitro, was not completely obliterated and cyclic AMP was partially induced in the target cells, showing that they still displayed enzymic activity in vivo. Moreover, although the A subunit possesses three potential sites for cleavage by furin, furin was not involved in the partial toxicity and cyclic AMP induction observed. These data suggest that target cells have a nick mechanism that operates at sites other than those around Arg192 or those recognized by furin, which generates an active fragment by processing the A subunit after toxin binding to the cell membrane.
\end{abstract}

Keywords: heat-labile enterotoxin, enterotoxigenic Escherichia coli, nicking, furin

\section{INTRODUCTION}

Enterotoxigenic Escherichia coli produces a heat-labile enterotoxin (LT), which is structurally and biologically similar to cholera toxin (CT) from Vibrio cholerae and which causes severe diarrhoea in humans. CT and LT are composed of an A subunit with toxic biological activities and a $B$ subunit that binds the toxin to $G_{M 1}$ ganglioside receptor on the target cells (Finkelstein, 1973; Clements \& Finkelstein, 1979; Holmgren, 1981; Spangler, 1992). The A subunit consists of $A_{1}$ and $A_{2}$ fragments, which are linked by a disulfide bond. A proteolytic nick of CT or LT A subunit at position Arg192 or nearby residues is introduced between the $A_{1}$ and $A_{2}$ fragments after secretion from $V$. cholerae. The A subunits of both toxins are totally unnicked and accumulate in the periplasmic space of E. coli (Clements \& Finkelstein, 1979; Pearson \& Mekalanos, 1982; Mekalanos et al., 1983; Neill et al., 1983; Finkelstein et al., 1983; Booth et al., 1984; Hirst et al., 1984).

Free $A_{1}$ fragments activate adenylate cyclase of the target cells in vitro by catalysing ADP-ribosylation of

\footnotetext{
Abbreviations: $C T$, cholera toxin; FCS, foetal calf serum; $L T$, heat-labile enterotoxin; LT-A, A subunit of heat-labile enterotoxin; rLT-B, recombinant $B$ subunit of heat-labile enterotoxin; LT(CE), normal heat-labile enterotoxin from cell extract; $P F$, rabbit skin permeability.
}

GTP-binding protein $\left(\mathrm{G}_{\mathrm{s}}\right)$, whereas the unnicked or nicked A subunits without reduction do not (Gill \& King, 1975; Mekalanos et al., 1979). In fact, the free $A_{1}$ fragment reportedly catalyses the transfer of the ADPribose moiety of NAD to arginine or other simple guanidium compounds such as agmatine (ADP-ribosyltransferase activity) or the ADP-ribosylation of the 42 or $43 \mathrm{kDa}$ protein of the cell membrane (Moss et al., 1979; Freissmuth \& Gilman, 1989; Moss \& Vaughan, 1990). Therefore, the ADP-ribosyltransferase activity and activation of the adenylate cyclase with ADPribosylation of $\mathrm{G}_{\mathrm{s}}$ in vivo are known to be caused by the free $A_{1}$ fragment (Moss \& Vaughan, 1990).

As the unnicked LT shows the same toxicity as the nicked LT in the ileal loop test (Rappaport et al., 1976; Clements \& Finkelstein, 1979) and CHO cell assay (Kunkel \& Robertson, 1979; Tsuji et al., 1984), a trypsin-like protease might completely nick the amino acid sequence around Arg192 in these assays. Moreover, though the biological activity of unnicked LT is lower than that of nicked LT in the rabbit skin permeability (PF) test (Clements \& Finkelstein, 1979; Takeda et al., 1981), unnicked LT is considered to be partially nicked at Arg192 or nearby residues by an unknown protease from target cells.

However, in this paper, we demonstrate that LT has partial toxicity and induces cyclic AMP independent of 
Table 1. Summary of the mutant toxins prepared in this study

\begin{tabular}{|c|c|}
\hline $\begin{array}{l}\text { Mutant } \\
\text { name }\end{array}$ & $\begin{array}{l}\text { Amino acid deletion(s) or } \\
\text { substitution(s) }\end{array}$ \\
\hline \multicolumn{2}{|l|}{ Group I } \\
\hline R192G & Substitution from Arg192 to Gly 192 \\
\hline Del192 & Deletion of Arg192 \\
\hline \multicolumn{2}{|l|}{ Group II } \\
\hline Del192-193 & Deletion of Arg192 and Thr193 \\
\hline R192G + Del193-194 & $\begin{array}{l}\text { R192G plus deletion of Thr193 and } \\
\text { Ile194 }\end{array}$ \\
\hline R192G + Del194-195 & $\begin{array}{l}\text { R192G plus deletion of Ile194 and } \\
\text { Thr195 }\end{array}$ \\
\hline Del192-194 & Deletion from Arg192 to Ile194 \\
\hline Del192-195 & Deletion from Arg192 to Thr195 \\
\hline Gly192-194 & Deletion of Gly192-Gly193-Gly194 \\
\hline \multicolumn{2}{|l|}{ Group III } \\
\hline$R 192 G+R 138 G$ & $\begin{array}{l}\text { Double substitutions from Arg to } \\
\text { Gly at positions } 192 \text { and } 138\end{array}$ \\
\hline $\mathrm{R} 192 \mathrm{G}+\mathrm{R} 143 \mathrm{G}$ & $\begin{array}{l}\text { Double substitutions from Arg to } \\
\text { Gly at positions } 192 \text { and } 143\end{array}$ \\
\hline$R 192 G+R 146 G$ & $\begin{array}{l}\text { Double substitutions from Arg to } \\
\text { Gly at positions } 192 \text { and } 146\end{array}$ \\
\hline$R 192 G+R 148 G$ & $\begin{array}{l}\text { Double substitutions from Arg to } \\
\text { Gly at positions } 192 \text { and } 148\end{array}$ \\
\hline
\end{tabular}

the nick in the Arg192 region. Moreover, potential cleavage sites of furin are also present in the LT A subunit (LT-A) from positions 138 to 141 ( $\mathrm{Arg}^{138}$-LeuHis-Arg ${ }^{141}$ ), from 141 to 146 ( $\operatorname{Arg}^{141}$-Asn-Arg ${ }^{143}$-GluTyr-Arg ${ }^{146}$ ) or from 146 to 151 (Arg ${ }^{146}$-Asp-Arg ${ }^{148}$-TyrTyr-Arg ${ }^{151}$ ). The peptides from 141 to 146 and 146 to 151 are likely to be cleavage sites for furin, but three arginines are essential (Nakayama et al., 1992). Therefore, we determined whether sites of furin cleavage were involved in partial toxicity, as they are in diphtheria (Tsuneoka et al., 1993) and shiga (Garred et al., 1995) toxins.

\section{METHODS}

Bacteria. The plasmid EWD299 (Dallas et al., 1979) carrying the LT gene from a porcine enterotoxigenic E. coli strain was used. E. coli MV 1184 was used as competent cells. The vectors Bluescript II SK(+)-1 and SK(-)-1 were purchased from Toyobo.

Cell lines. BW5147 myeloma cells were donated by the Foundation for Promotion of Cancer Research, Setagaya, Tokyo, Japan. Furin-deficient $\mathrm{L}_{0} \mathrm{~V}_{0}$ cells were kindly given by Professor E. Mekada, University of Kurume, Fukuoka, Japan.

Site-directed mutagenesis. Site-directed mutagenesis was performed by means of the polymerase chain reaction (PCR) as described by Saiki et al. (1985). A Bluescript II SK $(-)-1$ vector carrying the LT gene without the HindIII-EcoRI or $X b a \mathrm{I}-H i n \mathrm{dIII}$ fragments of the LT-A gene was prepared. Detailed procedures and PCR conditions were as described by Ito et al. (1991).
The first PCR generated products with a mutation or a deletion. The second PCR generated HindIII-EcoRI or XbaIHindIII fragments that carried a mutation or a deletion in LTA. The second PCR product was sequenced using a DNA sequencer (Applied Biosystems) and ligated into the HindIIIEcoRI or HindIII-XbaI site of the LT gene.

Purification of mutant and normal toxins. Mutant toxin E112K and recombinant LT B subunit (rLT-B) were prepared as described previously (Tsuji et al., 1990, 1994). Each toxin was purified by Bio-gel A5m or immobilized-D-galactose affinity chromatography as described by Clements \& Finkelstein (1979) and Uesaka et al. (1994). Detailed procedures for culture of the cells, isolation of cell extracts and purification of LT by successive chromatography in TEAN buffer $(50 \mathrm{mM}$ Tris/HCl, $1 \mathrm{mM}$ EDTA, $3 \mathrm{mM} \mathrm{NaN}_{3}, 0 \cdot 2 \mathrm{M} \mathrm{NaCl} \mathrm{pH} \mathrm{7.4)}$ were as described by Tsuji et al. (1990). The LT fraction purified from EWD299 strain contained mainly unnicked LT and a small amount of nicked LT (Clements \& Finkelstein, 1979). Therefore, this sample with or without trypsin treatment was referred to as $\mathrm{LT}(\mathrm{CE})$ or nicked $\mathrm{LT}$, respectively. Trypsin treatment was performed by mixing $20 \mu \mathrm{g}$ toxin with $1 \mu \mathrm{g}$ trypsin at $37^{\circ} \mathrm{C}$ for $60 \mathrm{~min}$, as described by Rappaport $e t$ al. (1976).

\section{NAD: agmatine ADP-ribosyltransferase assay.}

The formation of ADP-ribosylagmatine was determined as described by Moss et al. (1993). Each sample contained $50 \mathrm{mM}$ potassium phosphate $\mathrm{pH} 7 \cdot 5,100 \mu \mathrm{M}$ GTP, $5 \mathrm{mM} \quad \mathrm{MgCl}_{2}$, nicotinamide[U- $\left.{ }^{14} \mathrm{C}\right]$ adenine dinucleotide $\left[6 \times 10^{4}\right.$ c.p.m. $\left.\left(9 \cdot 25 \times 10^{2} \mathrm{~Bq}\right)\right], 10 \mathrm{mM}$ agmatine, $0 \cdot 1 \mathrm{mg}$ ovalbumin $\mathrm{ml}^{-1}$ and other materials as described in a total volume of $300 \mu \mathrm{l}$. As ADP-ribosyltransferase activity of the toxin is activated by Triton X-100 (Tsuji et al., 1991), 0.1\% (v/v) Triton X-100 was added to the reaction mixture. Toxins were then added. After $60 \mathrm{~min}$ at $30^{\circ} \mathrm{C}$, each sample was transferred to AG1-X2 columns which were washed four times with $1.25 \mathrm{ml}$ water. Eluate containing $\left[\mathrm{U}-{ }^{14} \mathrm{C}\right]$ adenine dinucleotide ribosylagmatine was radioassayed.

Rabbit ileal loop test. The rabbit abdomen was opened under anaesthesia and $5 \mathrm{~cm}$ loops were ligated to the mid part of the small intestine as described by Lycke et al. (1992). Various duplicate doses of purified toxins in $1.0 \mathrm{ml}$ TEAN buffer $\mathrm{pH} 7.4$ were injected into the loops and the abdomen was closed. After $18 \mathrm{~h}$, the rabbits were killed and the contents and length of the ligated loop were measured. Fluid accumulation was expressed as volume per unit length $\left(\mathrm{ml} \mathrm{cm}^{-1}\right)$ and represented means of duplicates with one rabbit. We performed four independent experiments and the results presented are means $\pm S D$ from the four rabbits.

Rabbit skin permeability test. The PF test was performed as described by Craig (1964). Each sample was diluted with borate gelatin buffer and then $0 \cdot 2 \mathrm{ml}$ was subcutaneously injected into the rabbit skin at four spots for each experiment. After $24 \mathrm{~h}, 0.01 \%(\mathrm{w} / \mathrm{v})$ Evans blue $\left[1 \mathrm{ml}(\mathrm{kg} \mathrm{body} \mathrm{wt})^{-1}\right]$ was injected intravenously and $1 \mathrm{~h}$ later blue spots were scored. Toxin activity was recorded as the dose required to produce a mean blueing score of 25 from the four spots.

CHO cell assay. Morphological changes in $\mathrm{CHO}$ cells were examined essentially as described previously (Tsuji et al., 1984). The CHO cells, which were grown in Eagle minimal essential medium (MEM; Eagle, 1959) containing 10\% (v/v) foetal calf serum (FCS) under $6 \%(\mathrm{v} / \mathrm{v}) \mathrm{CO}_{2}$ at $37^{\circ} \mathrm{C}$, were removed from culture vessels by treatment of trypsin. After the cells had been washed with the above medium, they were suspended in MEM containing $1 \%(\mathrm{v} / \mathrm{v}) \mathrm{FCS}$ and $3 \times 10^{3}$ cells 
were added to each chamber of an eight-chamber slide (Miles Scientific). They were then challenged with toxin for $18 \mathrm{~h}$ in a $\mathrm{CO}_{2}$ incubator at $37^{\circ} \mathrm{C}$. The cells were fixed with absolute ethanol and stained with Giemsa for examination of their morphology.

Determination of the cyclic AMP response of myeloma cells or furin-deficient $\left(L_{0} V_{0}\right)$ cells. Myeloma BW5147 or furindeficient $\mathrm{L}_{0} \mathrm{~V}_{0}$ cells $\left(1 \times 10^{6}\right)$ were cultured in MEM or HAM (Ham, 1965) containing 10\% FCS for 2 or $4 \mathrm{~d}$, respectively. After three washes with the above medium, the cells were placed in fresh medium and treated with the normal and mutant LTs at the given concentrations. They were incubated for the given periods and harvested in $0.4 \%(\mathrm{v} / \mathrm{v})$ acetic acid followed by boiling at $100{ }^{\circ} \mathrm{C}$ for $5 \mathrm{~min}$. The samples were centrifuged and the concentration of cyclic AMP was determined in the supernatants using a kit (Pharmacia) as described by Lycke et al. (1992).

\section{RESULTS}

\section{Selection of the mutants}

The mutant toxins prepared in this study are described in Table 1 and the mutation sites are shown in Fig. 1. Since it has been reported that R192G has partial toxicity (Grand et al., 1994), we first prepared R 192G and Del192 and determined their partial activity in the ileal loop test (Fig. 2).

The nick site from Arg192 to Thr195 is also important for toxin activation (Klapper et al., 1976; Clements \& Finkelstein, 1979; Mekalanos et al., 1983; Booth et al., 1984; Ichinose et al., 1992). To determine whether this site might be involved in toxicity, we next prepared deletion mutants as described under group II (Table 1).

As shown in Fig. 1, three kinds of potential furin cleavage sites are also present in LT-A. To determine the role of furin in partial toxicity, we prepared mutant toxins with double mutations, one at position 192 and one at position 138, 143, 146 or 148 (group III of Table 1). Each mutant toxin was then purified and characterized.

\section{Assembly of A and B subunits of the purified toxins}

As shown in Fig. 3, R192G and Del192 separated into two bands on SDS-PAGE gels corresponding to the A and $B$ subunits. The mobilities of the subunits were identical to those of LT(CE) and were not affected by trypsin treatment, suggesting that the A subunits of the mutant toxins are not digested by trypsin. The mutant toxins in groups II and III exhibited A and B subunits that were not affected by trypsin treatment.

Moreover, densitograms of these gels were scanned at $660 \mathrm{~nm}$. The ratio (from 35 to $35.5 \%$ ) of the mutant A to the normal B subunit was identical to that of the normal LT $(37 \cdot 2 \%)$. As Bio-gel and immobilized Dgalactose have affinity for $B$ subunit but not for $A$ subunit, all of the eluted A subunit from these columns would be expected to bind to the $\mathrm{B}$ subunit.

These data suggest that the assembly of mutant A and B subunits is not affected as a consequence of the mutations that were introduced.

\section{Comparison of NAD: agmatine ADP- ribosyltransferase activity of each mutant}

As shown in Table 2, ADP-ribosyltransferase activity was determined. R192G and Del192 had no enzymic activity at a dose of $320 \mu \mathrm{g}$ with or without Triton X100 , though 5 or $40 \mu \mathrm{g}$ of the nicked LT or LT(CE), respectively, showed some activity. The high dose of LT(CE) also had low enzymic activity as described by Moss et al. (1993). Some LT was nicked during the purification procedure, as described by Clements \& Finkelstein (1979). Moreover, the mutant toxins in group II and group III also had no enzymic activity at a dose of $320 \mu \mathrm{g}$ with trypsin treatment.

These data suggest that these mutant toxins do not release an active fragment when treated with trypsin. We then determined whether each mutant toxin had biological activity in vivo.

\section{Comparison of biological activity of each mutant toxin by the PF test}

As shown in Fig. 4, the dose response curves of R192G and Del192 were determined by the PF test. The dose required to produce a blueing score of 25 was $0.7 \pm 0.3$, $6 \cdot 3 \pm 3 \cdot 0,4 \cdot 5 \pm 2 \cdot 0,11 \cdot 5 \pm 5 \cdot 0,>5 \times 10^{3}$ or $>5 \times 10^{3} \mathrm{ng}$ for nicked LT, LT(CE), R192G, Del192, E112K or rLT$B$, respectively. Thus, the activity of $L T(C E)$ was less than that of the nicked LT and similar to that of R192G and Del192. Moreover, the doses required to produce a blueing score of 25 for the mutants in group II and III were $5 \cdot 0 \pm 4 \cdot 0$ to $17 \cdot 0 \pm 7 \cdot 2$, which were indistinguishable for those of LT(CE), R192G and Del192.

These data suggest that nicking around Arg192 and furin sites is not involved in the partial PF activity of the toxin. We then confirmed this finding in the $\mathrm{CHO}$ cell assay.

\section{Biological activities of each mutant toxin in the $\mathrm{CHO}$ cell assay}

In the $\mathrm{CHO}$ cell assay, the dose response curves of R192G and Del192 were determined as described in Fig. 5 . The doses required to cause $50 \%$ elongation were $1 \cdot 1 \pm 1 \cdot 9,1 \cdot 4 \pm 1 \cdot 0,17 \cdot 7 \pm 12 \cdot 0,14 \cdot 1 \pm 7 \cdot 7,>5 \times 10^{3}$ and $>5 \times 10^{3} \mathrm{ng}$ for the nicked LT, LT(CE), R192G, Del192, E112K and rLT-B. Thus, the toxicity of both mutants was about 10 -fold less than that of LT. Moreover, the doses required for $50 \%$ elongation for the mutant toxins in group II and III were from $14 \cdot 3 \pm 4 \cdot 2$ to $22 \cdot 5 \pm 4 \cdot 2$, suggesting the toxicity of these mutants is identical to that of R192G and Del192 in the CHO cell assay.

These data suggest that all of the mutant toxins in Table 1 have partial toxicity. We then determined whether they induced cyclic AMP in target cells. 




Fig. 2. Diarrhoeal activity of R192G, Del192, LT, E112K and rLT$B$ in the ileal loop test. The test was performed as described in Methods. Values are means $\pm S D$ of four independent experiments. Mean values, which gave $0.5 \mathrm{ml} \mathrm{cm}^{-1}$ ileal loop activity, were $44 \cdot 6 \pm 25,56 \cdot 2 \pm 30,316 \pm 157,363 \pm 120,>10^{4}$ and $10^{4} \mathrm{ng}$ of nicked LT, LT(CE), R192G, Del192, E112K and rLT$B$, respectively. $O$, Nicked $L T ; 0, L T(C E) ; \square, R 192 G$ with trypsin treatment; $\square$, Del192 with trypsin treatment; $\triangle$, E112K with trypsin treatment; $\boldsymbol{\Delta}$, rLT-B.

\section{Comparison of the induction of cyclic AMP by the mutant toxins in myeloma cells}

As shown in Fig. 6, cyclic AMP induction by R192G or Del192 was determined. LT(CE), R192G and Del192 induced $366 \pm 44,239 \pm 56$ and $127 \pm 56$ or $201 \pm 11$, $211 \pm 39$ and $150 \pm 44$ fmol cyclic AMP per $10^{6}$ cells for 5 or $7 \mathrm{~h}$ inoculation, respectively. R192G or Del192 induced lower cyclic AMP levels than LT(CE), though
Fig. 1. Amino acid sequence of the $A$ subunit of LT. The arrows ( $\downarrow$ ) show the potential sites for furin cleavage at Asn 142, Asp147 or Asn152. The three underlines between Arg138 and Arg151 show the peptides recognized by furin. 'Mutant sites' show the positions of arginine residues substituted by glycines in group III mutants. The black triangles ( $\boldsymbol{\nabla})$ show the known nick site (Klapper et al., 1976; Finkelstein et al., 1983; Mekalanos et al., 1983; Booth et al., 1984; Ichinose et al., 1992; Grant et al., 1994).

Fig. 3. SDS-polyacrylamide gel electrophoresis of purified normal and mutant LTs. Toxins R192G, Del192 and E112K were purified and digested with trypsin as described in Methods. Each sample was heated with $10 \mathrm{mM} \mathrm{DTT}$ at $100^{\circ} \mathrm{C}$ for $2 \mathrm{~min}$. SDS-PAGE was performed on a $15 \%$ acrylamide gel as described by Laemmli (1970). Lanes: 1, R192G without trypsin treatment; 2, Del192 without trypsin treatment; 3, normal LT without trypsin treatment; 4, R192G with trypsin treatment; 5, Del192 with trypsin treatment; 6 , normal LT with trypsin treatment; 7 , E112K with trypsin treatment; 8, E112K without trypsin treatment; 9, rLT-B.

the latent time before inducing the maximal response was similar. Moreover, the mutants in group II and III also induced cyclic AMP in myeloma cells.

For 5 or $7 \mathrm{~h}$ incubation, the values of cyclic AMP were from $110 \pm 62$ to $210 \pm 55$ or from $85 \pm 6 \cdot 0$ to $120 \pm$ 
Table 2. ADP-ribosyltransferase activity of normal and mutant toxins

\begin{tabular}{|c|c|c|}
\hline $\begin{array}{l}\text { Toxin } \\
\text { concn } \\
(\mu \mathrm{g})\end{array}$ & $\begin{array}{c}\text { Triton } \\
\mathrm{X}-100 \\
(0 \cdot 1 \%)\end{array}$ & $\begin{array}{c}{\left[\mathrm{U}-{ }^{14} \mathrm{C}\right] \text { adenine }} \\
\text { dinucleotide } \\
\text { ribosylagmatine } \\
\text { concn" } \\
\text { (c.p.m.) }\end{array}$ \\
\hline \multicolumn{3}{|c|}{ LT (nicked) } \\
\hline $2 \cdot 5$ & - & 0 \\
\hline $5 \cdot 0$ & - & 602 \\
\hline $10 \cdot 0$ & - & 2300 \\
\hline $20 \cdot 0$ & - & 4210 \\
\hline $20 \cdot 0$ & + & 4520 \\
\hline \multicolumn{3}{|l|}{$\mathrm{LT}(\mathrm{CE})$} \\
\hline 20 & - & 0 \\
\hline 40 & - & 280 \\
\hline 80 & - & 760 \\
\hline 160 & - & 1250 \\
\hline 160 & + & 1320 \\
\hline \multicolumn{3}{|c|}{ Mutant (R192G or Del192) } \\
\hline 80 & - & 0 \\
\hline 160 & - & 0 \\
\hline 320 & - & 0 \\
\hline 320 & + & 0 \\
\hline \multicolumn{3}{|c|}{ E112K and rLT-B } \\
\hline 320 & - & 0 \\
\hline 320 & + & 0 \\
\hline
\end{tabular}

"Determined as radioactivity induced by the toxin minus radioactivity induced by TEAN buffer ( $\mathrm{pH} 7 \cdot 4$, blank). Values are means of two independent experiments.



Fig. 4. Comparison of toxicity of R192G or Del192 with that of LT, E112K and RLT-B by the PF test. The test was performed as described in Methods. Blueing scores were determined as described by Craig (1964) and the values are means \pm SD for three independent experiments. $O$. Nicked LT; $\bigcirc$, LT(CE); $\square$, R192G with trypsin treatment; $\square$, Del192 with trypsin treatment; $\triangle, E 112 \mathrm{~K}$ with trypsin treatment; $\Delta, \mathrm{rLT}-\mathrm{B}$.

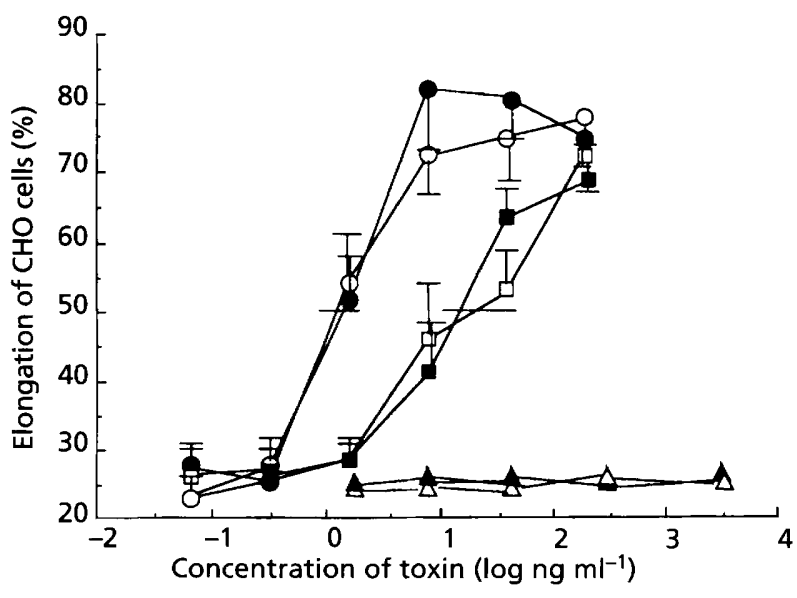

Fig. 5. Comparison of elongation activity of R192G or Del192 with that of LT, E112K and RLT-B in the CHO cell assay. The assay was performed as described in Methods. Values are means \pm SD for three independent experiments. $O$, Nicked LT; - LT(CE); $\square$, R192G with trypsin treatment; $\square$, Del192 with trypsin treatment; $\triangle$, E112K with trypsin treatment; $\boldsymbol{\Delta}, \mathrm{rLT}-\mathrm{B}$.

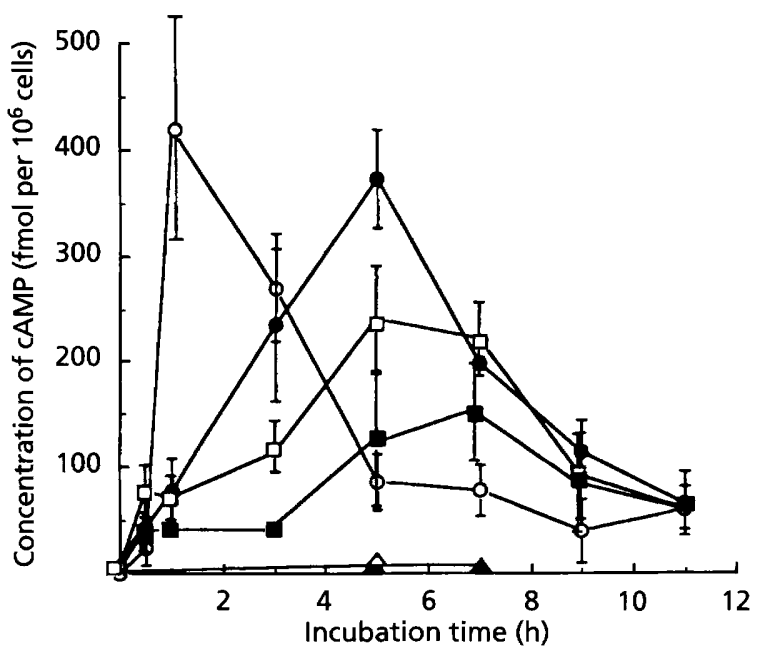

Fig. 6. Comparison of cyclic AMP induction by the mutant toxin with LT, E112K and rLT-B. Myeloma cells $\left(10^{6}\right)$ were cultured in MEM containing $10 \%$ FCS and then transferred to fresh medium. The toxin was added at a final concentration of $10 \mu \mathrm{g} \mathrm{ml}^{-1}$. After incubation, the samples were prepared as described in Methods and the cyclic AMP concentration determined using a cyclic AMP kit. The induction of cyclic AMP (fmol per $10^{6}$ cells) was determined as concentration induced by the toxin minus concentration induced by TEAN buffer (control). Values are means $\pm S D$ of three experiments. $O$, Nicked LT; LT(CE); $\square$, R192G with trypsin treatment; Del192 with trypsin treatment; $\triangle$, E112K with trypsin treatment; $\Delta$, rLT-B.

$65 \mathrm{fmol}$ per $10^{6}$ cells. The cyclic AMP responses slightly differed, but were similar to those of R192G and Del192, indicating that nicking around $\operatorname{Arg} 192$ and furin sites is not involved in cyclic AMP induction in target cells. 
Table 3. Cyclic AMP induction by normal and mutant toxins in furin-deficient cells

Furin-deficient cells $\left(1 \times 10^{6}\right)$ were incubated with $10 \mu \mathrm{g} \mathrm{ml}^{-1}$ of each toxin and lysed after 3, 5, 7 and $9 \mathrm{~h}$. The concentration of cyclic AMP was determined as described in Methods. The induction of cyclic AMP was determined as the concentration induced by the toxin minus the concentration induced by TEAN buffer (control). Values are means \pm SD from three independent experiments.

\begin{tabular}{|c|c|c|c|c|}
\hline \multirow[t]{2}{*}{ Mutant } & \multicolumn{4}{|c|}{ Cyclic AMP concn (fmol per $10^{6}$ cells) } \\
\hline & $3 \mathrm{~h}$ & $5 \mathrm{~h}$ & $7 \mathrm{~h}$ & $9 \mathrm{~h}$ \\
\hline $\mathrm{LT}(\mathrm{CE})$ & $39 \cdot 2 \pm 8 \cdot 3$ & $203 \cdot 3 \pm 35$ & $192 \cdot 3 \pm 30$ & $186 \cdot 7 \pm 11$ \\
\hline R192G & ND & $92 \cdot 1 \pm 30$ & $148 \cdot 2 \pm 25$ & $171 \cdot 1 \pm 16$ \\
\hline Del192 & $25 \cdot 0 \pm 6 \cdot 5$ & $98 \cdot 7 \pm 25$ & $159 \cdot 4 \pm 22$ & $181 \cdot 7 \pm 21$ \\
\hline Del192-192 & ND & $69 \cdot 4 \pm 28$ & $137 \cdot 4 \pm 45$ & $181 \cdot 7 \pm 14$ \\
\hline R192G + Del193-194 & ND & $64 \cdot 5 \pm 32$ & $143 \cdot 9 \pm 28$ & $197 \cdot 8 \pm 12$ \\
\hline R192G + Del194-195 & ND & $64 \cdot 5 \pm 32$ & $143 \cdot 9 \pm 28$ & $197 \cdot 8 \pm 12$ \\
\hline Del192-194 & $15 \cdot 6 \pm 7 \cdot 9$ & $129 \cdot 7 \pm 45$ & $181 \cdot 7 \pm 31$ & $186 \cdot 8 \pm 14$ \\
\hline Del192-195 & $23 \cdot 6 \pm 8 \cdot 0$ & $106 \cdot 8 \pm 35$ & $148 \cdot 2 \pm 21$ & $203 \cdot 3 \pm 31$ \\
\hline Gly192-194 & $21 \cdot 8 \pm 10 \cdot 0$ & $38 \cdot 4 \pm 29$ & $127 \cdot 5 \pm 38$ & $181 \cdot 7 \pm 10$ \\
\hline $\mathrm{E} 112 \mathrm{~K}$ & ND & ND & $<6.0$ & ND \\
\hline rLT-B & ND & ND & $<6.0$ & ND \\
\hline
\end{tabular}

However, it is possible that the point mutations blocking the furin sites left one or two other sites that might be involved in activation of toxin in vivo. Therefore, we examined the importance of furin for toxin activation in furin-deficient cells.

\section{Cyclic AMP induction by mutant toxins and LT in furin-deficient $L_{0} V_{0}$ cells}

Cyclic AMP induction by mutant toxins from group I and group II was compared with that of normal LT in furin-deficient cells. As shown in Table 3, cyclic AMP was induced by LT(CE), R192G, Del192 and each deletion mutant from Arg192 to Thr195. Though the latent time to induce the maximal cyclic AMP response was about $5 \mathrm{~h}$ in myeloma cells (Fig. 6), the latent time in furin-deficient cells was longer. At this time, we do not understand the reason for this observation.

These data suggest that a deficiency of furin does not extinguish cyclic AMP induction in the target cells and that the three kinds of furin sites are not involved in toxicity.

\section{DISCUSSION}

The nick at Arg192 or nearby residues is thought to be essential for activation of biological and enzymic activity of CT or LT (Klapper et al., 1976; Finkelstein et al., 1983; Mekalanos et al., 1983; Booth et al., 1984; Ichinose et al., 1992; Grant et al., 1994). However, although mutant toxins lacking these nick sites have no ADP-ribosyltransferase activity, they showed partial toxicities in the ileal loop test (Fig. 2), PF test (Fig. 4) and $\mathrm{CHO}$ cell assay (Fig. 5) and induced less cyclic AMP (Fig. 6 and Table 3) than LT. These nick sites are therefore essential for ADP-ribosyltransferase activity, but not for biological activity and cyclic AMP induction. This is consistent with the fact that partial toxicity and adjuvant activity is independent of nicking at Arg192 (Grant et al., 1994; Dickinson \& Clements, 1995).

Thus, how might these mutant toxins activate the adenylate cyclase/cAMP system? There are two possible mechanisms apart from nicking of the abnormal A subunit. (1) There might be another pathway by which the abnormal A subunit activates adenylate cyclase in vivo. (2) The abnormal unnicked A subunit might directly activate adenylate cyclase dependent on or independently of ADP-ribosyltransferase activity.

There are no reports indicating another pathway that activates adenylate cyclase by CT except for the ADPribosylation of $\mathrm{G}_{\mathrm{s}}$, which inhibits its GTPase activity (Freissmuth \& Gilman, 1989). In this system, free A subunit is essential. Therefore, it is unclear whether or not there is another pathway.

The abnormal A subunits did not show ADP-ribosyltransferase activity (Table 2). Therefore, the mutant A subunit cannot activate adenylate cyclase dependent on ADP-ribosyltransferse. Moreover, there is no information to show that the A subunit can directly activate adenylate cyclase independently of ADP-ribosyltransferase.

Therefore, there might be a nick mechanism that generates an active fragment by processing the $A$ subunit, after toxin binding to the cell membrane. Since unnicked LT stayed on the cell surface longer than nicked LT (Tsuji et al., 1984), the A subunit might be nicked by a membrane protease.

A subunits might be nicked after they penetrate cells. Crystal analysis of LT (Sixma et al., 1991) has indicated how the A subunit might penetrate the membrane and 
reach the target protein. $B$ subunits bind to the $G_{M_{1}}$ ganglioside receptor and the polysaccharide of $G_{M_{1}}$ forms a loop around the B subunits and pushes the A subunit into the cell membrane. The toxin might also enter the cell by endocytosis and a function of the Golgi apparatus is necessary to generate the $A_{1}$ fragment (Orlandi et al., 1993). It is possible that after the A subunit penetrates the cell, it is processed by an intracellular endopeptidase normally used for posttranslational processing of a protein other than furin.

Therefore, LT has partial toxicity independent of the nick sites at Arg192 or nearby residues. To demonstrate partial toxicity, nicking mechanisms that are independent of furin may function subsequent to toxin-binding to the cell membrane to release an active A fragment.

\section{ACKNOWLEDGEMENTS}

This work was supported by a Grant-in-Aid for Scientific Research from the Ministry of Education, Science and Culture of Japan. We thank Professor E. Mekada and Dr T. Umada, Institute of Life Science, Kurume University, Fukuoka for the gift of the furin-deficient cells; Professor Keinosuke Okamoto, Department of Biochemistry, Faculty of Pharmaceutical Science, Tokushima Bunri University, Yamashiro-cho, Tokushima, 770, Japan for helpful advice and Miss Sachie Asai for technical assistance.

\section{REFERENCES}

Booth, B. A., Boesman-Finkelstein, M. \& Finkelstein, R. A. (1984). Vibrio cholerae hemagglutinin/protease nicks cholera toxin. Infect Immun 45, 558-560.

Clements, J. D. \& Finkelstein, R. A. (1979). Isolation and characterization of homologous heat-labile enterotoxins with high specific activity from Escherichia coli cultures. Infect Immun 24, 760-769.

Craig, J. P. (1964). A permeability factor (toxin) found in cholera stools and culture filtrates and its neutralization by convalescent cholera sera. Nature 207, 614-616.

Dallas, W. S., Gill, D. M. \& Falkow, S. (1979). Cistrons encoding Escherichia coli heat-labile toxin. J Bacteriol 139, 850-858.

Dickinson, B. \& Clements, J. D. (1995). Dissociation of Escherichia coli heat-labile enterotoxin adjuvanticity from ADP-ribosyltransferase activity. Infect Immun 63, 1617.

Eagle, H. (1959). Amino acid metabolism in mammalian cell cultures. Science 13, 432-437.

Finkelstein, R. A. (1973). Cholera. Crit Rev Microbiol 2, 553-623. Finkelstein, R. A., Boesman-Finkelstein, M. \& Holt, P. (1983). Vibrio cholerae hemagglutinin/lectin/protease hydrolyzes fibronectin and ovomucin: F. M. Burnet revisited. Proc Natl Acad Sci USA 80, 1092-1095.

Freissmuth, M. \& Gilman, A. G. (1989). Mutations of $G_{\mathrm{s} \alpha}$ designed to alter the reactivity of the protein with bacterial toxins. J Biol Chem 264, 21907-21914.

Garred, O., van Deurs, B. \& Sandvig, K. (1995). Furin-induced cleavage and activation of shiga toxin. J Biol Chem 270, 10817-10821.

Gill, D. M. \& King, C. A. (1975). The mechanism of action of cholera toxin in pigeon erythrocyte lysates. J Biol Chem 250, 6424-6432.
Grant, C. C. R., Messer, R. J. \& Cieplak, W. (1994). Role of trypsinlike cleavage at arginine 192 in the enzymatic and cytotonic activities of Escherichia coli heat-labile enterotoxin. Infect Immun 62, 4270-4278.

Ham, R. G. (1965). Clonal growth of mammalian cells in a chemically defined, synthetic medium. Proc Natl Acad Sci USA 53, 288-293.

Hirst, T. R., Randall, L. L. \& Hardy, S. J. (1984). Cellular location of heat-labile enterotoxin in Escherichia coli. J Bacteriol 157, 637-643.

Holmgren, J. (1981). Actions of cholera toxin and the prevention and treatment of cholera. Nature 292, 413-417.

Ichinose, Y., Tsuji, T., Ehara, M., Miyama, A. \& Naito, T. (1992). A protease from Vibrio cholerae nicks arginine at position 192 from the $\mathrm{N}$-terminus of the heat-labile enterotoxin A subunit from enterotoxigenic Escherichia coli. Eur J Epidemiol 8, 743-747.

Ito, W., Ishiguro, H. \& Kurosawa, Y. (1991). A general method for introducing a series of mutations into cloned DNA using the polymerase chain reaction. Gene 102, 67-70.

Klapper, D. G., Finkelstein, R. A. \& Capra, J. D. (1976). Subunit structure and N-terminal amino acid sequence of the three chains of cholera enterotoxin. Immunochemistry 13, 605-611.

Kunkel, S. L. \& Robertson, D. C. (1979). Purification and chemical characterization of the heat-labile enterotoxin produced by enterotoxigenic Escherichia coli. Infect Immun 25, 586-596.

Laemmli, U. K. (1970). Cleavage of structural proteins during the assembly of the head of bacteriophage T4. Nature 227, 680-685.

Lycke, N., Tsuji, T. \& Holmgren, J. (1992). The adjuvant effect of Vibrio cholerae and Escherichia coli heat-labile enterotoxins is linked to their ADP-ribosyltransferase activity. Eur J Immunol 22, 2277-2281.

Mekalanos, J. J., Collier, R. J. \& Romig, W. R. (1979). Enzymatic activity of cholera toxin. J Biol Chem 254, 5855-5861.

Mekalanos, J. J., Swartz, D. J., Pearson, G. D. N., Harford, N., Groyne, F. \& de Wilde, M. (1983). Cholera toxin genes; nucleotide sequence, deletion analysis and vaccine development. Nature 306, 551-557.

Moss, J. \& Vaughan, M. (1990). ADP-ribosylating toxins and G proteins. Washington, DC: American Society for Microbiology. Moss, J., Garrison, S., Oppenheimer, N. J. \& Richardson, S.H. (1979). NAD-dependent ADP-ribosylation of arginine and proteins by Escherichia coli heat-labile enterotoxin. J Biol Chem 254 6270-6272.

Moss, J., Stanley, S. J., Vaughan, M. \& Tsuji, T. (1993). Interaction of ADP-ribosylation factor with Escherichia coli enterotoxin that contains an inactivating lysine 112 substitution. J Biol Chem 268, 6383-6387.

Nakayama, K., Watanabe, T., Nakagawa, T., Kim, W. S., Nagahama, M., Hosaka, M., Hatsuzawa, K., Kondo-Hashiba, K. \& Murakami, K. (1992). Consensus sequence for precursor processing at mono-arginyl sites. J Biol Chem 267, 16335-16340.

Neill, R. J., Ivins, B. E. \& Holmes, R. K. (1983). Synthesis and secretion of the plasmid-coded heat-labile enterotoxin of Escherichia coli in Vibrio cholerae. Science 221, 289-290.

Orlandi, P. A., Curran, P. K. \& Fishman, P. H. (1993). Brefeldin A blocks the response of cultured cells to cholera toxin. J Biol Chem 268, 12010-12016.

Pearson, G. D. N. \& Mekalanos, J. J. (1982). Molecular cloning of Vibrio cholerae enterotoxin genes in Escherichia coli K-12. Proc Natl Acad Sci USA 79, 2976-2980.

Rappaport, R. S., Sagin, J. F., Pierzchala, W. A., Bonde, G., Rubin, 
B. A. \& Tint, H. (1976). Activation of heat-labile Escherichia coli enterotoxin by trypsin. J Infect Dis 133, S41-S54.

Saiki, R. K., Scharf, S., Faloona, F., Mullis, K. B., Horn, G. T., Erlich, H. A. \& Arnheim, N. (1985). Enzymatic amplification of $\beta$-globin genomic sequences and restriction site analysis for diagnosis of sickle cell anemia. Science 230, 1350-1354.

Sixma, T. K., Pronk, S. E., Kalk, K. H., Wartna, E. S., van Zanten, B. A. M., Witholt, B. \& Hol, W. G. J. (1991). Crystal structure of a cholera toxin-related heat-labile enterotoxin from Escherichia coli. Nature 351, 371-377.

Spangler, B. D. (1992). Structure and function of cholera toxin and the related Escherichia coli heat-labile enterotoxin. Microbiol Rev 56, 622-647.

Takeda, Y., Honda, T., Taga, S. \& Miwatani, T. (1981). In vitro formation of hybrid toxins between subunits of Escherichia coli heat-labile enterotoxin and those of cholera toxin. Infect Immun 34, 341-346.

Tsuji, T., Honda, T. \& Miwatani, T. (1984). Comparison of effects of nicked and unnicked Escherichia coli heat-labile enterotoxin on Chinese hamster ovary cells. Infect Immun 46, 94-97.

Tsuji, T., Inoue, T., Miyama, A., Okamoto, K., Honda, T. \& Miwatani, T. (1990). A single amino acid substitution in the A subunit of Escherichia coli enterotoxin results in a loss of its toxic activity. $J$ Biol Chem 265, 22520-22525.

Tsuji, T., Inoue, T., Miyama, A. \& Noda, M. (1991). Glutamic acid112 of the A subunit of heat-labile enterotoxin from enterotoxigenic Eschericha coli is important for ADP-ribosyltransferase activity. FEBS Lett 291, 319-321.

Tsuji, T., Kato, M., Kato, Y., Kawase, H., Imamura, S. \& Miyama, A. (1994). Construction of plasmids useful to the $B$ subunit of cholera toxin from Vibrio cholerae or a heat-labile enterotoxin from enterotoxigenic Escherichia coli. Eur J Epidemiol 10, 393-398.

Tsuneoka, M., Nakayama, K., Hatsuzawa, K., Komada, M., Kitamura, N. \& Mekada, E. (1993). Evidence for involvement of furin in cleavage and activation of diphtheria toxin. J Biol Chem 268, 26461-26465.

Uesaka, Y., Otsuka, T., Lin, Z., Yamazaki, S., Yamaoka, J., Kurazono, H. \& Takeda, Y. (1994). Simple method of purification of Escherichia coli heat-labile enterotoxin and cholera toxin using immobilized galactose. Microb Pathog 16, 71-76.

Received 22 October 1996; revised 20 December 1996; accepted 23 December 1996. 